\title{
Deambulação e espacialidade em Paranoia (1963) ${ }^{1}$
}

\author{
Ana Luiza Rodrigues Gambardella, \\ Joubert Lancha, \\ Paulo Cesar Castral*
}

\begin{abstract}
Resumo A deambulação enquanto prática estética é abordada, dentro do movimento surrealista, como forma de apreensão do espaço e evocação da beleza convulsiva. O presente artigo objetiva abordar o deambular por São Paulo, dos anos 1960, como elemento estruturante na construção do fotolivro Paranoia (1963) com poesias de Roberto Piva e fotografias de Wesley Duke Lee. Por meio de uma leitura estrutural dos vinte poemas inscritos no livro, objetiva-se verificar a possibilidade de mapear e analisar os caminhos adotados pelos artistas e concluir, qualitativamente, como se dá a construção do imaginário da cidade na obra.
\end{abstract}

Palavras-chave: deambulação, surrealismo, fotolivro, Paranóia.

\section{Deambulación y espacialidad en Paranoia (1963)}

Resumen La deambulación como práctica estética se aborda, dentro del movimiento surrealista, como una forma de aprehensión del espacio y evocación de la belleza convulsiva. El presente artículo pretende acercarse a lo deambular de Sao Paulo, desde los años 1960, como elemento estructurante en la construcción del fotilibro Paranoia (1963) con poesía de Roberto Piva y fotografías de Wesley Duke Lee. Através de una lectura estructural de los veinte poemas inscritos en el libro, el objetivo es verificar la posibilidad de mapear y analizar los caminos adoptados por los artistas y concluir, cualitativamente, cómo se lleva a cabo la construcción del imaginario de la ciudad en la obra.

Palabras clave: deambulación, surrealismo, fotolibro, Paranóia.

\section{Deambulation and spatiality in Paranoia (1963)}

Abstract Deambulation as an aesthetic practice is approached, within the surrealist movement, as a form of apprehension of space and evocation of convulsive beauty. This article aims to approach the deambulation through São Paulo, from the 1960s, as a structuring element in the construction of the photobook Paranoia (1963) with poetry by Roberto Piva and photographs by Wesley Duke Lee. Through a structural reading of the twenty poems inscribed in the book, the goal is to study the possibility of mapping and analyzing the paths adopted by the artists and to conclude, qualitatively, how the construction of the city's imaginary occurs in the work.

Key words: deambulation, surrealism, photobook, Paranóia. 
O que os autores surrealistas mais prezam é o prazer de andar sem rumo pela cidade [...] (JACQUES, 2012, p.124)

\section{A}

prática do caminhar pelo espaço urbano possibilita a criação de uma visão sensível sobre o mesmo e é utilizada por diversos artistas a fim de compreender como as relações ali presentes se compõem, assim como suas modificações e o cotidiano. Uma estética própria do percorrer a cidade se inaugura com essas ações e o seu estudo traz uma nova camada de entendimento deste espaço vivido. No entanto, este tipo de experiência com o espaço material vivido não é de fácil representação. Temos a adoção de relatos, filmagens, fotografias, desenhos, ou mesmo a não representação posterior. No entanto, a pluridade significante percebida ao longo da vivência demanda algo mais que a simples figuração de um ponto de vista em tais meios. A tensão gerada na influência recíproca entre os meios, seja pela co-presença, seja pela relação estrutural, legitima o caráter hibrido desses projetos artísticos que nos trazem o tempo e o espaço do caminhar pela cidade.

[...] explorar a pé a cidade e penetrar em seus significados é uma arte tal como a escultura, a pintura, a arquitetura, mas também como a fotografia, o cinema, a poesia que nos contam muitas vezes com mais eficácia do que os urbanistas, os fenômenos mais dificilmente legíveis da cidade atual. (CARERI, 2017, p.101)

Careri (2013), em seu livro Walkscapes, caminhar como prática estética, faz o debate do caminhar no espaço urbano como potencializador estético do espaço banal. Segundo o autor, o caminhar foi utilizado como forma de antiarte durante todo o início do século. Grupos como o Dadá, com o flâneur, os Surrealistas, com a deambulação, e Situacionistas com a deriva, trazem o caminhar como ação fundante de suas práticas estéticas. Dentro dessas práticas indicadas, interessa em especial, a colocação de Careri sobre a prática surrealista da deambulação.

* Ana Luiza Rodrigues Gambardella é Arquiteta e Urbanista, Mestranda do Programa de Pós-graduação em Teoria e História em Arquitetura e Urbanismo do Instituto de Arquitetura e Urbanismo da USP, ORCID <https:// orcid.org/0000-0003-24420862>. Joubert Lancha é Arquiteto e Urbanista, Professor e atual Diretor do Instituto de Arquitetura e Urbanismo da USP, ORCID <https://orcid.org/00000002-1690-6857>. Paulo Cesar Castral é Arquiteto e Urbanista, Professor do Instituto de Arquitetura e Urbanismo da USP, ORCID <https://orcid.org/00000002-6329-7847>
Os surrealistas têm a convicção de que o espaço urbano pode ser atravessado como a nossa mente; de que, na cidade, pode se revelar uma realidade não visivel. O surrealismo é uma espécie de investigação psicológica da própria relação com a realidade urbana, uma operação já praticada com sucesso por meio da escrita automática e dos sonhos hipnóticos, e que também pode voltar a ser proposta diretamente ao se atravessar a cidade. (CARERI, 2013, p. 82-83)

O fotolivro Paranoia (1963) - com poesias de Roberto Piva (1937-2010) e fotografias de Wesley Duke Lee (1931-2010) -, é uma obra que nos traz o olhar surrealista sobre uma cidade brasileira, São Paulo. Piva participa do grupo fundador do Grupo Surrealista de São Paulo em 1963, juntamente com Claudio Willer e João da Rocha², e tem o fotolivro Paranoia considerado pela revista La Breche n'08 como o primeiro livro de poesia delirante publicado no Brasil (XXX, 1965 in: WILLER, 2014). 
10 presente trabalho foi realizado com apoio da Coordenação de Aperfeiçoamento de Pessoal de Nível Superior - Brasil (CAPES) - Código de Financiamento 001.

2 Únicos três autores citados no Dicionário Geral do Surrealismo de 1965 (ROCHA, 2014).

3 Texto original: "Paranoia est le premier livre de poésie délirante publié em brésilien. Piva, dont la formation intellectuelle est profondément marquée par la culture italienne a pris son inspiration dans le grands classiques de la décadence, d'où l'exubérance de l'image propre aux peuples latins. Freud et Lautreamónt ont eu pour lui la plus grande importance. Enfin, la plus moderne littérature beat nord-américaine lui a transmis la fascination des néons et l'hallucination par la métropole métallique qu'évoquent les photographies de São Paulo insérées dans son livre. " tradução livre dos autores, tal como as que se seguem.
Paranóia é o primeiro livro de poesia delirante publicado em português. Piva, com sua formação intelectual, é profundamente marcado pela cultura italiana assumiu sua inspiração pelos grandes clássicos da decadência, onde a exuberância da imagem é própria dos povos latinos. Freud e Lautréamont tinha grande importância para ele. Enfim, a mais moderna literatura dos beats norte-americanos transmitiu a ele a fascinação por neons e a alucinação da metrópole metálica evocadas pelas fotografias de São Paulo inseridas no livro. ${ }^{3}$ (XXX, 1965, p.125)

Percebe-se que o caminhar pela cidade realizado pelos autores nos conecta com uma representação construída na percepção de uma experiência muito própria do espaço vivido, ao mesmo tempo que abre possibilidades de leituras que demandam a participação ativa do leitor em um projeto de representação que não se fecha em si.

Neste artigo, então, objetiva-se, por meio do estudo do fotolivro Paranoia (1963), discutir uma experiência realizada no Brasil, mais especificamente em São Paulo, da prática de deambulação surrealista como processo de dotar de sentido a cidade pelo caminhar como ação estética, procurando caracterizar a contribuição desse olhar na abordagem do estudo sobre o urbano.

\section{A questão da deambulação}

O caminhar enquanto ação estética passa por diversos entendimentos através dos movimentos artísticos. Careri (2013) aponta diferenças entre as práticas do Dadá, surrealistas e situacionistas, indicando uma certa continuidade entre os grupos; segundo o autor:

O Dadá intuíra que a cidade podia ser um espaço estético no qual operar através de ações cotidianas e simbólicas, e convidara os artistas a abandonar as formas costumeiras de representação indicando a direção da intervenção dirigida no espaço público. O surrealismo - talvez sem ainda compreender completamente o seu alcance enquanto forma estética - utiliza o caminhar como meio através do qual indagar e desvelar as zonas inconscientes da cidade, aquelas partes que escapam do projeto e que constituem o que não é expresso e o que não é traduzivel nas representações tradicionais. Os situacionistas acusarão os surrealistas de não terem levado às extremas consequências as potencialidades do projeto dadaísta. O "fora da arte", a arte sem obra nem artista, o rechaço da representação e do talento pessoal, a busca de uma arte anônima coletiva e revolucionária serão colhidos, juntamente com a prática do caminhar, pela errância dos letristas/situacionistas. (CARERI, 2013, p.83)

A passagem da arte ao espaço urbano é o primeiro passo de uma série de excursões, flanâncias, deambulações e derivas como forma de antiarte (CARERI, 2013). O Dadá é o primeiro grupo a enfrentar o urbano enquanto espaço crítico de inferência.

O grupo pretende fazer a antiarte com suas intervenções, e uma das ações é retirar a arte dos espaços expositivos e trazer para o espaço cotidiano. Buscava-se a extinção da aura do autor, do objeto artístico e da criação individual de arte, uma estética coletiva, banal e democrática através da crítica ao status quo artístico.

É através do Dadá que se realiza a passagem do representar a cidade do futuro ao habitar a cidade do banal. [...] 
4 Dando a devida atenção à capital francesa, onde o autor escreve e onde os grupos artísticos irão realizar as suas errâncias.
A cidade dadaísta é uma cidade do banal que abandonou todas as utopias hipertecnológicas do futurismo. Para os dadaístas, a frequentação e a visita aos lugares insossos são uma forma concreta de realizar a dessacralização total da arte, a fim de alcançar a união entre arte e vida, entre sublime e cotidiano. (CARERI, 2013, p.74)

Uma nova estética foi inaugurada a partir do confronto da arte com o cotidiano, diferentemente de outros movimentos artísticos modernos, não se pretende representar um futuro, ou a modernidade com entusiasmo, mas sim, manter uma postura crítica às mudanças; uma crítica à velocidade das multidões a favor da lentidão do homem.

Essa lentidão é reproduzida através da figura do flâneur baudelairiano. Segundo Jaques, essa figura "deixa-se fascinar pela modernização, mas também reage a ela" (JAQUES, 2012, p.47), sendo fruto da mesma, que "ao mesmo tempo que faz parte do contexto urbano da modernização, faz uma crítica contundente à efetivação prática das grandes reformas urbanas" (p.47). Uma figura ambígua de fascínio e crítica.

O flâneur vive o cotidiano com os seus personagens mais renegados, "as prostituas, os trapeiros, os mendigos, os escroques" (JAQUES, 2012, p.46), personagens que são retirados do centro urbano através das transformações higienistas do começo do século XX nas capitais europeias ${ }^{4}$; esta figura, mais do que praticar a caminhada, se deixa vulnerável ao encontro da multidão, das possibilidades e da errância, segundo a autora, o flâneur busca a experiência do "choque" que essa nova conformação de sociedade é capaz de oferecer.

Segundo Jaques, a experiência do flâneur está diretamente ligada à demolição da cidade antiga para a construção da cidade modernizada, modificando "a experiência sensível, subjetiva, dos habitantes das grandes cidades, seja do ponto de vista fisiológico, seja, sobretudo, numa perspectiva psicológica." (JAQUES, 2012, p.49)

As incursões pela cidade que eram propostas pelos dadaístas têm, como característica, esse embate com a cidade modernizada, a experiência de uma cidade banal. O primeiro encontro é a caminhada Dadá pela cidade de Paris que se dá no dia 14 de abril de 1921, pretendendo abrir uma série de excursões urbanas. Este primeiro encontro é realizado na igreja de Saint-Julien-le-Pauvre.

Não sabemos qual dos artistas Dadá propôs o lugar - "uma igreja abandonada, pouco e mal conhecida, circundada à época de uma espécie de terrain vague cercado por paliçadas" - nem as razões da sua escolha. [...] um espaço a ser indagado por ser familiar e desconhecido, ao mesmo tempo não frequentado e evidente, um espaço banal e inútil que, como tantos, realmente não teria razão alguma de existir. (CARERI, 2013, p.77)

O grupo não intervinha no espaço físico de modo a deixar rastros de sua presença segundo Careri (2013), os únicos documentos das operações são os panfletos, artigos, fotos do grupo e narrações do ocorrido -, o interesse apresentado era de descobrir esteticamente os lugares já habitados da cidade, redescobrir o espaço ocupado através do banal. Um primeiro passo para a descoberta de novas realidades dentro do espaço urbano já construído. Esse contato com o banal pretendido pelo Dadá, inaugura, segundo o autor, a busca pelo inconsciente da cidade, e é o primeiro passo para as práticas surrealistas e situacionistas no espaço urbano. 
Com a exploração do banal, o Dadá dá início à aplicação das pesquisas freudianas do inconsciente da cidade, tema que será desenvolvido a seguir pelos surrealistas, pelos letristas e pelos situacionistas. (CARERI, 2013, p.77)

Jaques também indica essa influência nas ações posteriores, ao comentar sobre a visita Dadá à igreja de Saint-Julien-le-Pauvre.

Essa visita, a $1^{\text {a } ~ e ~ u ́ l t i m a ~ r e a l i z a d a ~ p e l o ~ g r u p o ~ D A D A, ~ p o d e ~ s e r ~ v i s t a ~ c o m o ~ u m ~ p r e n u ́ n c i o ~}$ das deambulações surrealistas, do estranhamento do que é banal e cotidiano, que vai ser um dos motes para a exploração de Paris por inúmeras experiências. (JAQUES, 2012, p.95)

A prática surrealista da deambulação considera que, além do espaço banal, há o espaço do inconsciente na cidade. O caminhar pelo espaço ativa as possibilidades de intervenção do inconsciente com o mundo material - conceito chave para a compreensão do surrealismo -, e propicia a criação do espaço enquanto representação. Para o surrealismo, o caminhar através do espaço urbano e da sua vida cotidiana é o meio de se encontrar a "beleza convulsiva", que, segundo Krauss (2014), pode-se dizer o centro da estética do surrealismo.

[...] esta estética se traduz por uma percepção da realidade transformada em representação. A surrealidade seria a natureza "convulsionada" por uma espécie de escrita. [...] Eu gostaria de acrescentar, embora não tenha espaço para me estender sobre o assunto aqui, que o que une toda a produção surrealista é precisamente esta percepção da natureza como representação, da matéria como escrita. Obviamente não se trata aqui de coerência morfológica e sim semiológica. (KRAUSS, 2014, p.122)

Ou ainda, segundo Careri (2013), o encontro com o "maravilhoso".

A cidade surrealista é um organismo que produz e esconde no seu seio territórios a serem explorados, paisagens nas quais perder-se e nas quais experimentar sem fim a sensação do maravilhoso cotidiano. (CARERI, 2013, p.83)

E conclui que o surrealismo utiliza o caminhar como forma de "indagar e desvelar as zonas inconscientes da cidade" (CARERI, 2013, p.83). A percepção do espaço urbano, seria, portanto, o contato com o maravilhoso e a postura de que o espaço urbano em si é uma representação.

O surrealismo, dentro desta visão, não pode ser compreendido como um maneirismo estilíistico, mas sim como uma visão de mundo, uma postura frente a realidade. (WILLER, 2008). Essa postura compreende a cidade enquanto representação, e, acima de tudo, enquanto campo associativo; o espaço material é sobreposto ao espaço do inconsciente e, através de relações de referenciação, transforma o espaço no campo de representação, abrindo possibilidades de associação analógica entre meios. O espaço urbano moderno é essencial para compreendermos a lógica do surrealismo, e comporta-se não somente como palco das representações, mas como contínuo espaço de referenciação.

A cidade enquanto campo convulsivo e fragmentado em uma cadeia de representações onde cada uma absorve a outra, a cidade enquanto processo permanente de referência, eis o que leva os surrealistas a afirmar que ela é moderna. (KRAUSS, 2014, p.156) 
5 Do original: The surreal is, semiotically speaking, a signifying effect, the confusion or a contradiction in conventional signifier-signified relations in representations and where a meaning is partially hidden, where the message appears 'enigmatic' regardless of how (or in what technological form) it has been produced.
Neste contexto, os surrealistas praticam o estranhamento do familiarizado, uma "etnologia às avessas", buscando o confronto com o banal de forma a questioná-lo, "tornar incompreensível o que é familiar no seu próprio cotidiano urbano." (JAQUES, 2012, p.16). Deste modo, os surrealistas buscam tornar o cotidiano em surreal, buscam a beleza convulsiva nas práticas usuais da vida urbana, uma visão que confronta a realidade e sua significação dada.

Em termos semióticos, a transformação de uma realidade banal, conhecida, em uma surrealidade está descrita em um efeito de quebra entre significante e significado. A quebra de expectativa de um dado contexto traz o desconhecido para a enunciação surrealista.

O surreal é, semioticamente falando, um efeito significante, a confusão ou contradição na relação convencional significante-significado nas representações e onde o significado é parcialmente escondido, onde a mensagem parece enigmática independentemente de como (ou em qual forma tecnológica) foi produzida ${ }^{5}$ (BATE, 2009, p.22)

A ação dos surrealistas no espaço urbano, quebra as convenções - cria um hiato representacional - do espaço urbano, seus personagens e dos elementos aos quais fazem parte.

Na prática da deambulação, temos uma "escrita automática no espaço real" (CARERI, 2013) com essa ação surrealista sobre o espaço urbano. A cidade é um sujeito autônomo e ativo, que transforma seus referentes constantemente. Essa abertura para a modificação constante dos significados mediante o território é uma ação de aproximação entre inconsciente e espaço material, assim como uma abertura ao acaso.

A ação de se deixar levar pelo território evoca o inconsciente de forma a diminuir e diluir as fronteiras entre sonho e realidade, assim como convida o caminhante a ter encontros inesperados. Ao deambular, se abre a possibilidade do encontro, colocar-se estrangeiro frente ao espaço cotidiano para causar a estranheza necessária, conforme colocado por Careri:

Navegar, caminhar, perder-se carregam consigo o tema do encontro com o Outro, levam a ser estrangeiro e a encontrar outros estrangeiros - é este que talvez me pareça ser hoje - o aspecto mais atual da errância. (CARERI, 2017, p.33)

Dentro das etnografias surrealistas, veremos o contato com as figuras das flanâncias baudelairianas, o outro que se encontra e evoca é a população marginalizada, notívaga, boêmia, os frequentadores das ruas e dos bares; "Outros" que estão localizados dentro do cotidiano urbano. Percebe-se que os surrealistas estavam vivendo a cidade à sua maneira (JAQUES, 2012).

\section{A cidade na literatura surrealista}

A vivência na cidade pelos surrealistas é retratada em livros do movimento. Dois exemplos significativos do relato de uma deambulação através da literatura são os livros Le Paysan de Paris, escrito em 1926 por Louis Aragon, e Nadja, escrito em 1928 por André Breton. Através dos dois livros, observa-se a ação deambulatória 
6 Trecho do livro "O Camponês de Paris" (1926), de Louis Aragon, consultado na tradução comentada por Flávia Cristina de Souza Nascimento, entregue como Dissertação apresentada ao Departamento de Teoria Literária do Instituto de Estudos da Linguagem da Universidade Estadual de Campinas, como requisito para obtenção do título de Mestre em Teoria Literária. Referência: NASCIMENTO, Flávia Cristina de Souza. O Camponês de Paris, de Louis Aragon (tradução comentada). Dissertação apresentada ao Departamento de Teoria Literária do Instituto de Estudos da Linguagem da Universidade Estadual de Campinas, como requisito para obtenção do título de Mestre em Teoria Literária. Orientadora: Prof. Dra. Vera Maria Chalmers. Campinas: Unicamp, 1991. dos surrealistas pela Paris do início do século XX por óticas semelhantes, porém com grandes particularidades.

O livro Le Paysan de Paris, é dividido em quatro (4) capítulos, o primeiro e o último, Prefácio para uma mitologia moderna e $O$ sonho do camponês, de caráter introdutório e conclusivo (JAQUES, 2012), apresentando um tom de denúncia e manifesto, segundo Nascimento (2006); e os dois capítulos centrais, A passagem da Opera e O sentimento da natureza no parque Buttes-Chaumont, formados por relatos deambulatórios.

Interessa observar a característica desse relato, Aragon elenca dois espaços distintos para descrever para o leitor; o primeiro - A passagem da Ópera -, mostra com riqueza de detalhes a descrição de uma passagem que será demolida pelas obras de urbanização de Haussmann, obras que reconfiguram a Paris do início do século XX, o autor descreve o lugar, suas características físicas enquanto caminha pelo espaço, e, ao mesmo tempo que exaustivamente nos relata o que vê, lembra de acontecimentos, das pessoas, moradores e passantes da vida noturna. Retrata, deste modo, uma Paris que deixará de existir a partir das obras que estão por vir, em uma atmosfera completa da vivência tida.

A loja seguinte é um café: Le Petit Grillon, de onde tenho mil lembranças. Durante anos frequentei-o ao menos uma vez por semana após o jantar, com amigos que eu acreditava, todos, verdadeiros. Conversávamos, jogávamos bacará, dados. À luz dos acontecimentos cotidianos, no farol giratório dos ganhos e das perdas, foi lá que comecei a sentir um pouco melhor a grandeza de um número muito reduzido desses companheiros de costume e a mesquinhez da maioria. ${ }^{6}$ (ARAGON, 1991, p. 44)

Neste trecho, observa-se uma concomitância entre o encontro com o café - um estabelecimento do local -, com as lembranças pessoais de Aragon; a questão da memória e do espaço material estão intimamente ligados durante o livro, o que demonstra uma permanência do autor nestes lugares e questões de afetividade, observa-se também que o relato trata de um espaço comum no cotidiano, dotado de uma vida própria.

O capítulo O sentimento da natureza no parque Buttes-Chaumont relata uma deambulação feita por Louis Aragon, André Breton e Marcel Noll, por um jardim localizado longe do centro e não amplamente conhecido, os autores caminham pelo espaço de forma a torná-lo labiríntico, com apontamentos diversos sobre o mesmo (NASCIMENTO, 2006). Apesar de se tratar de dois espaços com características muito diferentes (uma passagem no centro de Paris e um jardim na sua periferia), temos uma sensação labiríntica de descrição e surrealidade através das narrativas que vão sendo construídas pelas memórias, pelos devaneios e pela concatenação dos acontecimentos pelo autor.

[...] a Paris d'O camponês é uma espécie de microcosmo, graças à sua extraordinária diversidade: tanto a passagem quanto o parque revelam-se como verdadeiros mundos em abreviação, cada um desses dois lugares sendo o ponto de encontro de todos os espaços. (NASCIMENTO, 2006, p.63) 
7 Do original: La beauté sera CONVULSIVE OU ne sera pas.
Em Nadja não temos a divisão do livro em capítulos, o livro segue um fluxo de lembranças, reflexões e deambulações que aparentam jorrar nas páginas ao serem lidas. Na montagem da publicação, o autor usa desenhos e fotografias que compõem juntamente com o texto este universo particular do livro.

Segundo Jaques (2012), Nadja estabelece uma lógica através da perseguição do autor a uma personagem feminina encontrada nas ruas de Paris, "como se Breton decidisse perseguir a passante que Baudelaire deixou passar e sumir na multidão, e assim, através dela, ele (re)descobrisse sua própria cidade, e ela, a passante, passa a confundir com a experiência errática e com a própria cidade." (p.123)

Breton relata os encontros com a personagem através de uma estrutura de diário, do dia 04 de outubro ao dia 12 de outubro de 1926 (BRETON, 1998), onde os dois se perdem pela cidade enquanto mantém uma conversa sobre assuntos diversos. Durante a leitura do livro nos vemos mergulhados em um universo particular desse encontro e da Paris do século 1920, em uma mistura de descrição do ambiente e das situações ocorridas com as suas reflexões e lembranças, o espaço material e o subconsciente se tornam um, e permitem que a cidade e o autor sejam um organismo em união.

O autor e Nadja caminham pela cidade em busca de algo que não conseguem descrever: "perseguição de quê, eu não sei, mas perseguição, para assim recorrer a todos os artifícios de sedução mental" (BRETON apud. JAQUES, 2012, p.123). Buscam neste percurso, através do perder-se, o maravilhoso surrealista, a beleza convulsiva, citada por Breton na última frase do livro.

A beleza será CONVULSIVA OU não será7 . (BRETON, 1998, p.161, tradução própria)

O caráter deambulatório do livro extrapola o momento em que caminha com a personagem e relata uma consistência na prática pelo autor, que será vista por toda a prática surrealista.

No trecho recortado por Jaques (2012) é indicado essa prática da seguinte forma:

Pode-se, esperando, ter a certeza de encontrar comigo em Paris, de não passar mais do que dois ou três dias sem que me veja indo e vindo, lá pelo final da tarde, pelo Boulevard Bonne-Nouvelle, entre a gráfica do Mati e o Boulevard de Strassbourg. Não sei por que é para lá, de fato, que meus passos me levam, que vou para lá quase sempre sem objetivo determinado, sem nada decisivo a não ser esse dado obscuro de saber que ali vai acontecer isto (?). Quase não vejo, nesse percurso rápido, o que poderia, sem eu saber, constituir para mim um polo de atração, nem no espaço, nem no tempo. (BRETON apud. JAQUES, 2012, p.121)

Nos dois livros vemos a cidade como elemento central da narrativa, obtendo, segundo Jaques, o papel de protagonistas dos livros. Eles relatam o efêmero do cotidiano urbano, espaços e situações que são passageiras, que trazem conexões com outros lugares e acontecimentos e que não apresentam nenhuma característica monumental, espetacular a não ser o seu existir enquanto palco da vida.

No livro de Aragon, uma passagem que deixará de existir em poucos anos, demolida sob o contexto da modernidade e da higienização do espaço urbano e um passeio por um 
jardim descentralizado, pouco conhecido; os dois espaços são espaços interiorizados, passíveis de fechamento e, consequentemente, de transgressão se comparados com a realidade das vias. Aragon nos transporta para um recorte de uma Paris labiríntica, detalhada, particular e viva, mostra como, dentro de uma cidade podem conter várias localidades repletas de detalhes e particularidades.

Já no livro de Breton, vemos uma busca pelas ruas de Paris, pelos seus espaços frequentados através das errâncias. O autor erra de propósito, se perde conscientemente, e encontra nesse erro a beleza convulsiva no encontro entre espaço e inconsciente. Desenha, deste modo, a Paris da sua vivência, da vivência de seu grupo, e uma Paris que podemos conhecer através do seu relato. Com o autor conseguimos caminhar por um trajeto desenhado pelo mesmo, enxergar e ressignificar esses trajetos desenhados em um universo desenhado.

O espaço urbano e seus elementos são, portanto, de extrema importância para os dois trabalhos escolhidos e para os trabalhos desenvolvidos para os surrealistas como um todo, o contato do mundo material com o inconsciente é o que permite o acaso objetivo, relação importante de transformação e do entendimento da realidade enquanto representação.

\section{A cidade em Paranoia}

O fotolivro Paranoia, publicado em 1963, contém setenta e seis (76) fotografias dispostas regularmente ao longo de vinte (20) poesias e mostra igualdade de relevância entre fotografias e poesias. Quase que integralmente, temos uma fotografia ao lado de um trecho da poesia formando pares de páginas. Os dois meios mantêm uma interdependência estética relevante na leitura, mostrando que os artistas escolhem um suporte híbrido de representação e um discurso frente ao espaço vivido.

A fruição da obra nos leva a um caminhar pelo espaço urbano experienciado pelos artistas, o processo perceptivo do espaço urbano é sua representação, e camadas de compreensão do espaço urbano, seus personagens e a vida cotidiana são tecidas na assimilação do livro. Vê-se na fruição do livro que, o espaço urbano é expresso de forma visceral por toda a extensão do livro; durante a leitura, a cidade é palco, personagem e assunto da narrativa, mudando de posicionamento com muita fluidez e naturalidade.

A deambulação dos artistas, Roberto Piva e Wesley Duke Lee, é percebida através dessa presença marcante do espaço urbano no texto e fotografias. Esta característica traça uma proximidade com os livros do movimento surrealista, lembrando que, nos exemplos indicados: O Camponês de Paris mostra com riqueza de detalhes e com uma temporalidade alargada os devaneios do escritor, que emerge localidade com suas experiencias, apresenta ligações díspares ao estar presente no espaço e percebê-lo com atenção; e, Nadja mostra uma deambulação pelas ruas, aliada com a fotografia deste espaço, que hora referencia o espaço, hora traça o desencontro entre imagem visual e escrita. Ambos os exemplos criam uma imagem particular da cidade vivida, e o encontro dessas características em Paranoia reitera a indicação do fotolivro como surrealista, atribuída pelo próprio movimento através da revista La Breche $\mathrm{n}^{\circ} 08$, conforme indicado anteriormente. 
8 Esta análise do fotolivro é parte integrante do trabalho de pesquisa em desenvolvimento para dissertação de mestrado da autora.

90 contato com o fotolivro para a presente pesquisa vem sendo realizado ativamente durante os últimos três anos - até o momento da escrita do presente artigo.

10 Para a análise, foram desconsideradas as menções "São Paulo", pois, mesmo sendo específica, trata da cidade como um todo, não sendo possível mapear com a precisão necessária.

11 Foi utilizado o sistema google maps para a criação do mapa em questão. Disponível em: <https://drive.google.com/ open?id=116RuUhjEYh_RfEqOrHmr=-3ub1zursGqt\&uspsharing>.

120 poema No Parque do Ibirapuera também apresenta dois pontos demarcados no mapa, porém as localidades eram muito distantes para traçar um possível caminho percorrido.
Com a finalidade de desenvolver uma análise de Paranoia ${ }^{8}$, é realizado um exercício de leitura; em um primeiro momento, leituras atentas do fotolivro ${ }^{9}$ trouxeram as seguintes características: 1) a questão da cidade enquanto elemento de extrema importância na criação do trabalho para os artistas em questão; 2) uma familiaridade com os espaços retratados, transparecendo a convivência dos autores com estes espaços característica que presencia-se também nos exemplos trazidos -; 3) as fotografias não aparentam retratar necessariamente os espaços apontados pelo trecho de poesia ao qual se referem e nos seus respectivos pares de páginas.

Através da leitura dos poemas de Paranoia encontramos diversas indicações do espaço urbano de São Paulo, e, a partir desta constatação é traçada a hipótese de possibilidade de, a partir das indicações de espacialidades conhecidas (nomes de ruas, praças, entre outros), traçar possíveis caminhos adotados pelos artistas para as deambulações.

Com a hipótese levantada, inicia-se o processo de levantamento e verificação através da leitura geral do texto dos poemas. Nesse sentido, foram levantadas todas as menções ao espaço urbano e seus elementos, demonstrando visualmente uma densidade considerável de diálogo com este espaço. Dos vinte (20) poemas, um total de dezenove (19) tem indicações claras e citações do espaço material da cidade, totalizando um conjunto de cento e vinte e nove (129) menções ao espaço urbano e seus elementos, ao todo. Visualmente, percebe-se uma distribuição dessas citações de modo uniforme pelo texto do fotolivro, conforme constatado inicialmente.

Essa primeira aproximação reitera a ideia de que o fotolivro está imerso na realidade construída da cidade e mostra intimidade com o espaço vivido. O próximo passo da análise é a espacialização desse espaço vivido; para tanto, das cento e vinte e nove (129) menções, destacamos somente as que indicam um ponto específico e identificável da cidade, com a citação de nomes e localidades conhecidas ${ }^{10}$. Com este movimento, percebe-se uma diminuição considerável das citações, indo de cento de vinte e nove (129), para vinte e uma (21) citações específicas, um total de $16 \%$ das menções como um todo.

A leitura das menções específicas aponta dezessete (17) localidades mapeáveis na cidade de São Paulo, distribuídas em nove (9) poemas, observa-se uma grande diminuição do número de poemas com a localização de pontos específicos da cidade de São Paulo. Mapeando esses pontos através do mapa da cidade ${ }^{11}$, temos a seguinte configuração.

As localidades foram divididas pelos poemas em que se localizam, e somente dois ${ }^{12}$ (2) do conjunto de poemas localizados apresentam mais de um ponto demarcado no mapa de modo que se abre a possibilidade de um possível traçado de deambulação dos artistas. Os poemas em questão são Visão 1961 e Stenamina Boat; também foi elencado o poema Rua das Palmeiras, que, apesar de não ter dois pontos demarcados, pauta a extensão da Rua das Palmeiras, localizada no mapa em questão.

A partir de então, procurou-se em cada poema mapear visualmente como seriam esses caminhos traçados pelo poeta. Em todas as imagens a seguir, o caminho contínuo mostra a ligação dos pontos indicados automaticamente no mapa, e os caminhos tracejados a extensão das localidades indicadas e/ou caminhos prováveis enquanto pedestre. 


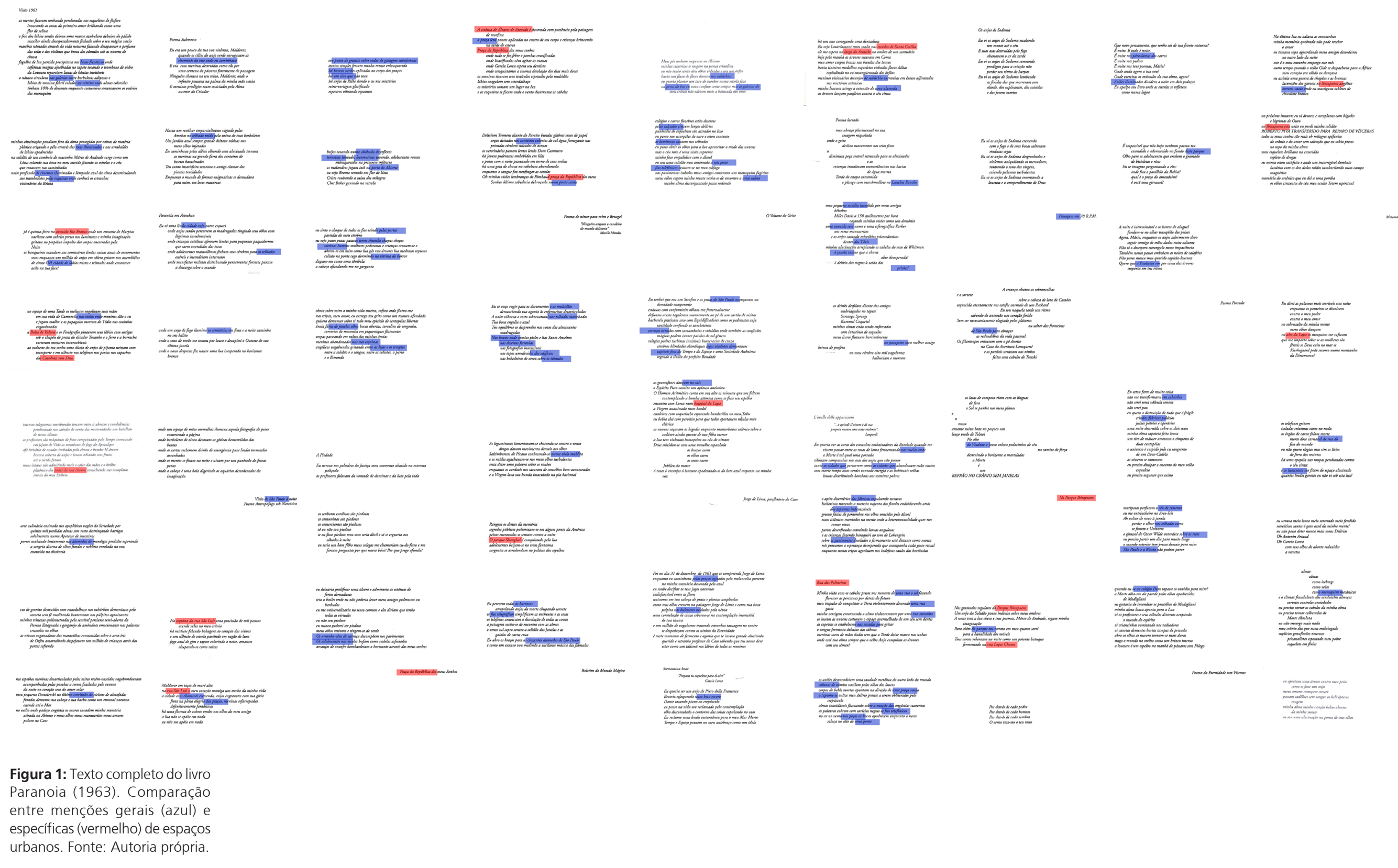

riSCO. v19_2021 - Edição Temática "Desenho" 
Figura 2: Localização dos pontos indicados em mapa da cidade de São Paulo - Indicação dos poemas mapeáveis. Autoria própria.

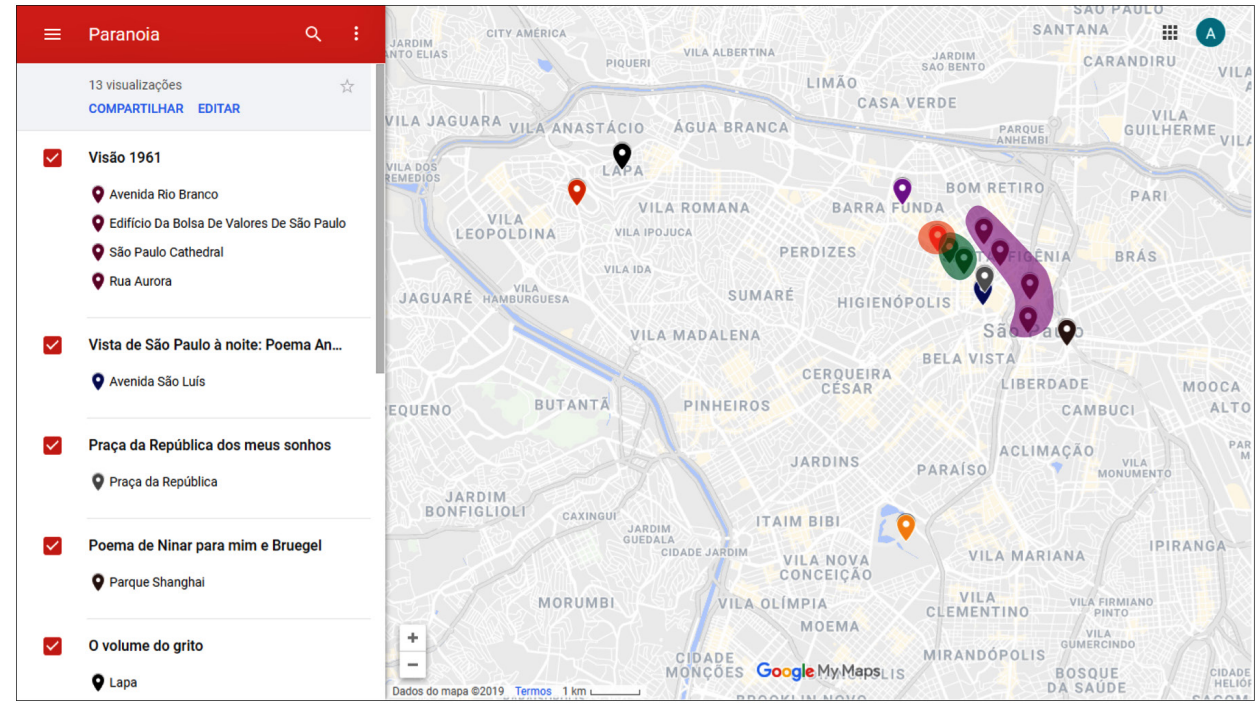

A partir da observação das imagens fotográficas em conjunto com os trechos de poema correspondentes, percebe-se uma desconexão entre o visual e o escrito, de modo que podemos constatar uma fotografia não documental dos locais indicados, característica observável na leitura do fotolivro e que pôde ser percebida com mais precisão neste mapeamento.

A partir da observação das imagens fotográficas em conjunto com os trechos de poema correspondentes, percebe-se uma desconexão entre o visual e o escrito, de modo que podemos constatar uma fotografia não documental dos locais indicados, característica observável na leitura do fotolivro e que pôde ser percebida com mais precisão neste mapeamento.

Mesmo quando o fotógrafo decide utilizar fotografias que retratem espaços públicos, no caso do poema Visão 1961, por exemplo, a imagem visual não corresponde com a citação da localidade, no caso, a Catedral da Sé; vemos, no entanto, enquanto referente fotográfico, um pátio com uma estátua. O mesmo ocorre nos outros poemas, quando se visualiza espacialidades ou elementos que não podem ser identificados com precisão sobre a localidade indicada no mapa e no texto do autor.

Neste exercício, percebe-se a dissociação entre significante e significado para a criação do olhar surreal. Quebra-se as expectativas de uma imagem fotográfica esclarecedora - em termos de visualização de uma localidade - e dota-se de novos significados a partir das associações possíveis na tensão entre texto e recorte fotográfico. O mesmo pode ser indicado ao se constatar a impossibilidade de traçado dos caminhos percorridos pelos autores, diferentemente do que encontramos nos exemplos trazidos - Nadja e O Camponês de Paris - a indicação e proximidade com a cidade real é impossibilitada pela falta de indicação precisa, mas, dialeticamente, é possível pela sua presença marcante. 

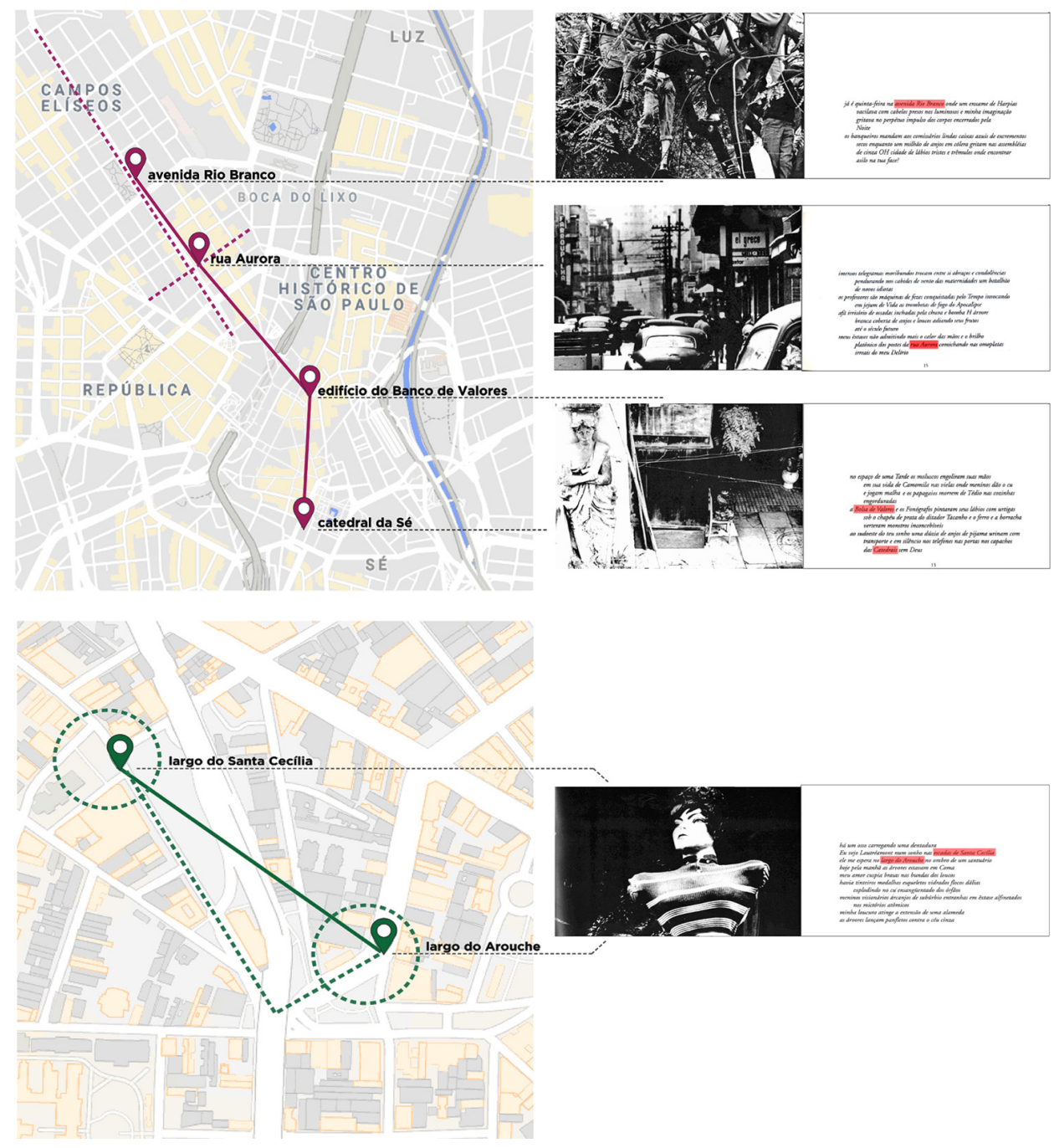

Figura 3: Mapeamento do poema Visão 1961. Os pontos localizados são: avenida Rio Brando, Rua Aurora, Banco de Valores e Catedral da Sé. Fonte: Autoria própria.

Figura 4: Mapeamento do poema Stenamina Boat. Os pontos demarcados são: largo do Santa Cecília e largo do Arouche. Fonte: Autoria própria.
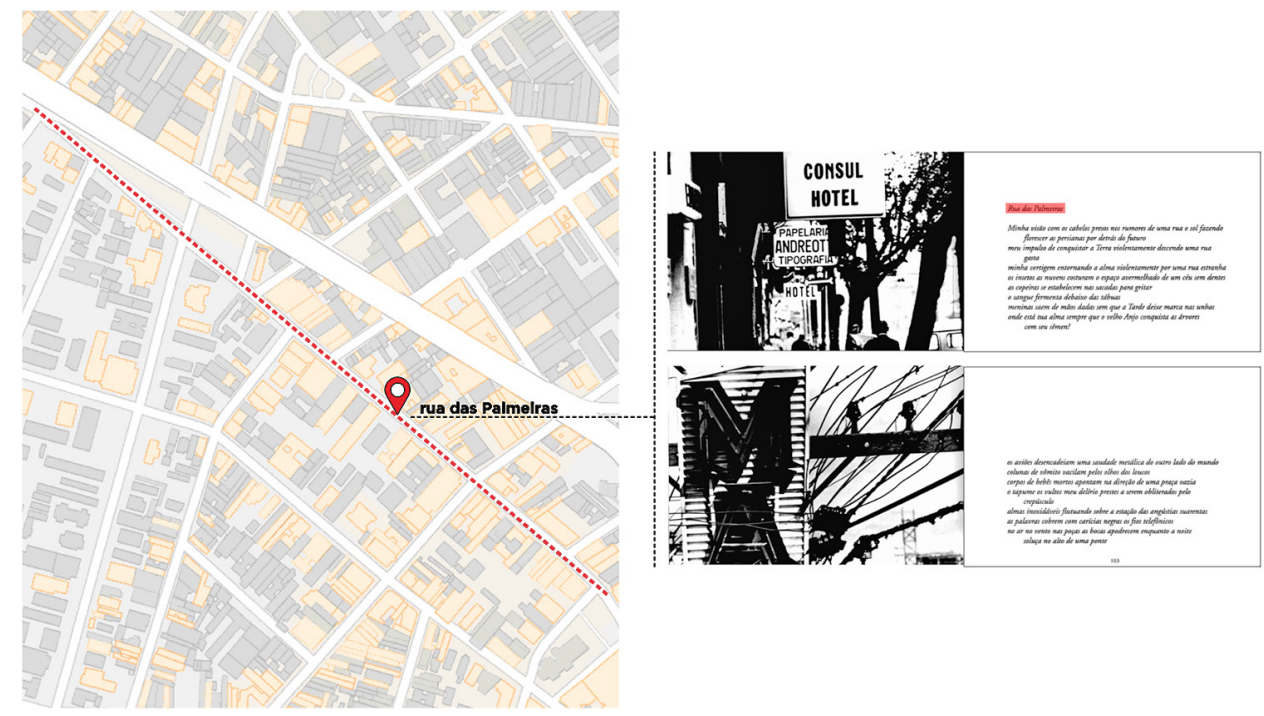

Figura 5: Mapeamento do poema Rua das Palmeiras. Fonte: Autoria própria. 
A abertura de possibilidades para criação de novos significados é percebido nessa dissociação. Tal característica é importante na compreensão do uso da fotografia dentro do campo surrealista, ou seja, é um meio que possibilita a criação de signos que, vazios de um significado próprio, são dotados de significados variados de acordo com a referencia a qual estão expostos. Esse processo se apresenta como chave de percepção no entendimento do mundo enquanto representação;

Na fotografia dentro do campo surrealista, o enquadramento nos dá a fração da realidade que nos compete para a criação do signo vazio, à espera do referencial externo e completude de sua significação; ele, portanto, nos mostra a fragmentação e descontinuidade do mundo percebido, com a possibilidade de recomposição em uma lógica não natural, sígnica e, neste sentido, não correspondente a uma representação diretamente relacionada à mimese. (GAMBARDELLA, CASTRAL, 2018, p.51)

Esses signos, semioticamente, chamam-se sincategoremas. Essa definição é levantada por Krauss (2014) a partir da taxonomia dos signos de Pierce, dentro da categoria dos signos indiciais. Sincategorema é o signo indicial que existe vazio de significado para uma significação temporária, portanto essa significação não tem espacialidade e temporalidade rigidamente definida. Cria-se o hiato representacional citado anteriormente. Segundo a autora:

São signos vazios que existem em toda linguagem verbal (palavras como isto, aquilo, hoje, amanhã, aqui, agora), quer dizer, palavras que se assemelham a continentes vazios à espera dos momentos especificos de contiguidade espacial ou temporal ("estou aqui", "hoje é quinta-feira"), que Ihes fornecem então um referente definido, mas apenas provisório. (KRAUSS, 2014, p.148)

No caso do fotolivro Paranoia, observa-se uma camada de representação que apresenta uma cidade não palpável, mas uma cidade surreal construída pelos artistas na experiência do deambular. O espaço vivido é, por si, um sincategorema aguardando as significações para dotar de significado. A cidade é o espaço vazio aguardando o encontro com o maravilhoso. E portanto, a correspondência ilustrativa entre imagem fotográfica e texto escrito não é essencial para a criação desta espacialidade vivida, pois ela mesmo já não é o espaço material, é o espaço surreal e constrói sobre si a dotação de sentido ininterruptamente.

Essa diferença entre a cidade em Paranoia e nos exemplos trazidos indica, em uma primeira instancia, uma postura frente ao espaço que está embebida destas referencias. A percepção do espaço já é realizada com uma ideia surrealista de enfretamento; os poemas escolhidos para a análise mostram que a cidade real não é o ponto chave de compreensão da cidade em Paranoia, mas sim, o encontro entre fotolivro e cidade, sua dissociação e embate, assim como é indiciado na dissociação das fotografias com a poesia.

Uma postura surreal frente a própria produção artística, mas sobretudo frente á cidade, constituída agora como produto do investimento simbólico de quem a olha e vivência. 
13 Alguns pontos são recorrentes em poemas distintos.

\section{Considerações}

A partir da visualização das menções à questão urbana e suas espacialidades, observase a afirmação da presença constante e expressiva da cidade no fotolivro. Constata-se que a cidade é elemento importante e de grande corpo para a obra em questão, e a mesma não se apresenta como palco, mas como personagem e elemento fundador e estruturante do livro.

A possibilidade de traçar os caminhos percorridos pelos autores nessa deambulação, por outro lado, perde sua força ao destacarem-se somente vinte e uma menções a localidades específicas da cidade, sendo dessas, dezessete pontos mapeáveis ${ }^{13}$ distribuídos em nove poemas. Dentro desta perspectiva limitada de delimitação dos caminhos, ao destacar os poemas com a possibilidade real de traçado, diminuímos o espectro em uma menor quantidade, o que dificultou o trabalho de reconstrução desses possíveis caminhos.

Percebe-se, no entanto, que há uma ambiência preponderante nessa localização geográfica dos pontos, no centro da cidade de São Paulo, indicando a convivência dos autores nesta localidade da cidade; além de uma predileção, dada pelo poeta, em retratar espaços corriqueiros, como vielas, becos, sacadas, entre outros. Outro dado importante é a desconexão entre imagem fotográfica e escrita - no sentido de retratar ou ambientar-se na localidade citada pelo autor.

Essas conclusões, reunidas, mostram que a hipótese de que é possível o redesenho de uma deambulação realizada pelos autores não se confirma, confirma-se, por outro lado, que a cidade relatada pelos autores é tratada enquanto ambiência, não enquanto relato. Deste modo, é certeira a predileção dos autores de não utilizar a fotografia enquanto documento de uma localização, mas trabalhar em concomitância com a palavra escrita, criando, juntamente com o texto, esta ambiência vivida pelos autores e relatada enquanto obra.

Com relação aos exemplos trazidos, pode-se inferir uma proximidade com Nadja(1928) pelo uso da imagem fotográfica como elemento importante para a construção da obra em conjunto com o texto, mas não enquanto relato de uma vivência específica do espaço, temporalmente e fisicamente no traçado de um caminho; e, pode-se inferir uma proximidade com O Camponês de Paris (1926) na criação de uma ambiência do espaço retratado.

O fotolivro, portanto, relata uma vivência na cidade, aliando presença e memória que a cidade carrega no encontro da experiencia do contato com o espaço urbano através das deambulações, dos encontros, desencontros e da vida cotidiana. Expressa o maravilhoso através dos encontros fortuitos e banais que a metrópole pode propiciar e enfrenta o espaço enquanto complexidade.

\section{Referências bibliográficas}

BATE, David. Photography and Surrealism: sexuality, colonialismo and social dissent. London: I.B. Tauris \& Co. Ltd, 2009. ISBN 978-1-86064-379-8.

BRETON, André. Nadja. 1998. Paris: Gallimard. ISBN 2-07-040130-8. 
CARERI, Francesco. Walkscapes: o caminhar como prática estética. 1 ed. São Paulo: Editora Gustavo Gili, 2013. ISBN 798-85-65985-16-1.

CARERI, Francesco. Caminhar e parar. São Paulo: Editora Gustavo Gili, 2017. ISBN 978-858452-090-9.

GAMBARDELLA, Ana Luiza; CASTRAL, Paulo Cesar. Fotolivro Paranoia: fotografia, surrealismo e espaço urbano. Revista Studium n40, p.47-59, dez. 2018. Campinas: Instituto de Artes da Unicamp. ISSN: 1519-4388. Disponível em: <https://www.studium.iar.unicamp.br/40/04/ index.html>.

JAQUES, Paola Berenstein. Elogio aos errantes. Salvador: EDUFBA, 2012. ISBN 978-85-2320870-7.

KRAUSS, Rosalind. O fotográfico. 1 ed. São Paulo: Editora Gustavo Gili, 2014. ISBN 978-8565985-61-1.

NASCIMENTO, Flávia. A Paris d'O camponês. Revista Letras n.70, p.59-79, set/dez 2006. Curitiba: Editora UFPR. DOI: <http://dx.doi.org/10.5380/rel.v70i0.4600>.

NASCIMENTO, Flávia Cristina de Souza. O Camponês de Paris, de Louis Aragon (tradução comentada). Dissertação apresentada ao Departamento de Teoria Literária do Instituto de Estudos da Linguagem da Universidade Estadual de Campinas, como requisito para obtenção do título de Mestre em Teoria Literária. Orientadora: Prof. Dra. Vera Maria Chalmers. Campinas: Unicamp, 1991.

WILLER, Claudio. Surrealismo: Poesia e Poética. In: GUINSBURG, J; LEIRNER, Sheila (org.). O Surrealismo. São Paulo: Editora Perspectiva, 2008. ISBN: 978-85-273-0816-8.

XXX. Le surrealisme à São Paulo. Revista La Brèche 8. Paris (França): Le Terrain Vague, novembro de 1965. p.127. Disponível em: <https://claudiowiller.wordpress.com/2014/10/30/a-famosa-resenha-em-la-breche-action-surrealiste/>. Aceso em: 04 maio 2017. 